\title{
Revisiting the Cultural Turn in Translation Studies
}

\author{
Lei DAl ${ }^{1, a,{ }^{*}}$ \\ ${ }^{1}$ Department of Translation and Interpretation, School of Foreign Languages, \\ Wuhan University of Technology, Wuhan, China \\ adailei218@whut.edu.cn
}

Keywords: Cultural turn, Translation studies, Context and text.

\begin{abstract}
This paper critically reviews the existing controversies over the cultural turn in Translation Studies by discussing the three major doubts cast onto this theory. The researcher begins by reviewing the background of the theory before analyzing the nature of the theory with an elaborate discussion on a religious translation dilemma. It is found that as a significant approach to Translation Studies, the cultural turn theory enables researchers to focus on the greater contextual factors influencing translatorial behavior rather than being myopic of the linguistic details. The paper thus contributes to a better understanding of the importance of using the theory as an analytical tool in translation research and an enhanced awareness of integrating text with context when studying translation.
\end{abstract}

\section{Introduction}

Translation and culture are inextricably intertwined. In order to overcome intercultural barriers, it is argued in the paper that the translator may not only need to consider text and language but also more broadly the source and target cultures. This stance is reflected in the broader "cultural turn" that Translation Studies has experienced since the 1990s. In practical terms this has meant that scholars have become more aware of the broad sociocultural context when considering the selection of translation strategies made by translators. This is what is known as "the cultural turn theory" $[1,2,3,4,5]$ and its corresponding approach to the studies of translation strategies is called the cultural studies approach. This paper will critically review the existing disputes over the cultural studies approach to Translation Studies.

\section{Origin and Development of the Concept}

Originating from anthropology, "cultural translation" far precedes the cultural turn in Translation Studies. In anthropology, cultural translation usually "refers to the act of describing for members of one cultural community how members of another interpret the world and their place in it" [6]. And it is generally agreed among anthropologists that "the introduction of remote and primitive tribal cultures to Western readers in Western languages is per se the translation between cultures" [6]. This is nonetheless different from the practices and procedures of contemporary translators. In their field survey, anthropologists successively played two roles, namely that of the source text author and the translator. This was because they had to sort out, describe and record the social norms, customs, ways of thinking, beliefs, written and / or spoken languages of the tribes before translating their findings for Western readers. To this end, it should be seen that cultural translation is theoretically a convergence of anthropology, intercultural communication and Translation Studies. 
The roots of cultural translation in Translation Studies can be traced to the works of Nida and Taber. In their seminal work The Theory and Practice of Translation (1969), two terms - linguistic translation and cultural translation - were used. A "linguistic translation" $[7,8]$ is one which only contains elements which can be directly derived from the source text wording, avoiding any kind of explanatory interpretation or cultural adjustment which cannot be justified on this basis. By contrast, a "cultural translation" $[7,8]$ is one in which additions are made which cannot be directly derived from the original source text wording; these might take the form of ideas culturally foreign to source text, or even elements which are simply included to provide necessary background information. As translation involves not only linguistic but also cultural conversion, it is natural that "Translation Studies gradually shifted from the purely-linguistic approach to the cultural approach, known as the cultural turn" $[1,8]$.

Of the works that are of relevance to the cultural turn and the cultural studies approach in Translation Studies, the writings of Bassnett and Lefevere in their collaborative work Translation, History and Culture (1990) constitutes an important collection and the beginning of a period in which the cultural turn held sway in Translation Studies. From the cultural perspective, this work deepens our understanding of the relations between translation and culture as well as the nature of translation practice and studies.

Our understanding of these points has been further clarified by Lefevere (1992), who argues that such issues as power, ideology, institution and manipulation are factors that restrict translation. He specifically deems cultural translation as a process of rewriting and manipulation [3]. In this sense, he claims that people involved in power positions, in order to ideologically manipulate the general public and consolidate their reigns, purposefully rewrite the literature translated from abroad. To contextualize these points, Lefevere [3] gave an example of Edward Fitzgerald, the $19^{\text {th }}$ century translator (or in Lefevere's words: "rewriter") of the Rubayait by Persian poet Omar Khayyám. Fitzgerald disdained Persians as inferior and felt he should take the helm to improve the original, meanwhile making it in line with the conventional Western aesthetic tastes. Despite his ethnocentrism, Fitzgerald's translation turned out to be a phenomenal commercial success. In another detailed case study, Lefevere [3] showed how the German translation of The Diary of Anne Frank intentionally toned down or deleted Anne's harsh words against Nazi atrocities to the Jews, thus rewriting Anne Frank's diary to pander to the public discourse of the mid 1950s when Germany was desperately struggling to escape its Nazi shadow.

This paper echoes the view of regarding the cultural turn as a shift of focus of Translation Studies from text-centered linguistic approach to the sociocultural approach beyond text. The very concept of culture in cultural turn refers to "the greater issues of context, history and convention" [10], not simply confined to the text-based culture. Some scholars reckon that the theory depreciates the text itself while exaggerating the restrictive force of the greater cultural factors on translation. Still others criticize it because it deviates translation from its nature and mission when using ideology as a determinant for the selection of translation strategies [11].Various doubts can be summarized with the following three questions:

Question one: does the text come into being under the influence of culture? In other words, is it the specific times that give birth to an ad-hoc text? Question two: what are the major differences between text-based culture and the greater culture beyond text? Question three: does the cultural turn in Translation Studies refer to the cultural preservation in line with the source culture or the cultural adaptation in line with the target culture? 


\section{Response to the First and Second Question}

Different from translation which involves such two different cultures as the source text and target text cultures, text at the time of being created, embodies exclusively the source culture. In this sense, text, as the product of source culture, represents ideology, convention, and other features of the specific times. However, the culture embedded freezes with the author "deceased" [12] the moment the text is created. So the answer to the first question is affirmative: texts are the cultural products of specific times. But when it comes to translation, the translator has to consider two cultures jointly: the source culture and the target culture.

In terms of the translation process, the greater culture beyond text is supposed to overshadow the text-based culture, because the former encompasses two cultures while the latter only reflects the culture in which it is born. Besides, the connotation of the greater culture "keeps expanding and will inevitably cover the stagnant text-based culture with the change of time, society, economy, purpose, position and ideology when the text is to be translated" $[13,14]$. The illusion that the text-based culture is also changing should be attributed to the varied interpretation of the text against a greater, dynamic, bi-cultural context. It is similar with a common experience in our daily life: buildings and trees outside the car window are seemingly running in reverse but the reality is they are not moving at all; it is our car that is moving ahead.

In this sense, the greater culture beyond text is open, dynamic and inclusive, illustrating the times when the text is translated while the text-based culture is closed, stagnant and parochial, only standing for the times when the text is created. When it comes to text processing, the translator may need to take account of both the text-based culture and the greater culture beyond text. But "when they are incompatible, priority should be given to the greater culture, particularly the target culture", a claim held by a host of translation theorists, especially those preferring the cultural studies approach and the descriptive approach $[13,15]$.

\section{Response to the First and Second Question}

Based on the above analysis of the cultural turn theory, this thesis maintains that there exists the text-based internal culture and the external culture beyond text. Besides being internal or external, cultures represent themselves in directions, namely, from the source culture to the target culture. The text embodies the cultural characteristics of a specific nation, so the translator has to make a choice: to preserve the source cultural features or, to adapt the source cultural images and references to the target cultural features. Next, a real case will be analyzed for any solution to this question.

When Christianity was first spread to the Arctic Arc where the Eskimos inhabit, to facilitate the understanding of the creed, missionaries made some adaptations when translating the Bible to the natives, among which, a typical case in point is "Lamb of God". As there were no lambs in the Arctic Arc but it was very common to see seals, so the missionaries translated lamb into seal. At first glance, this translation looks smart. But how did the Eskimos understand this translation which was adapted to their culture? Is it problematic? If yes, how so?

Inspired by the emphasis on the greater culture from the cultural turn theory, this version can be evaluated. With regard to the source culture, it is known that Christianity originated in Middle East, where lambs were domesticated firstly by the natives. So there is no wonder for the abundance of lamb-related expressions in the Bible.

However, with a closer look at the relations between the shepherd and lambs and those between Eskimos and lambs, it is easy to find the two dramatically different. The lamb, as meek as cute, can be domesticated while domestication involves a sense of 
responsibility, governance and adoration, not simply ruthless claims and exploitation. So in this sense, "lamb of God", besides representing an image of a sacrificial animal in Christian doctrine, serves as a transferred epithet: identifying the shepherd's affection for the lamb with God's affection for his people, which embodies his benevolence as well as authoritativeness.

By contrast, the relations between Eskimos and seals are like those between predator and prey. During the unforgivingly bleeding hunting, what can be seen is man trying to cheat or outwit the creature, without a vestige of benevolence. Therefore, when lamb was translated as seal, probably no Eskimos would perceive the deep affection that God has for lamb. The dramatically different relationships between lamb and god and between seal and Eskimos are illustrated with the figures below:

In effect, appropriate strategies can be selected, inspired by the cultural turn theory. The translator should make strategic selections based on the mental worlds of the interlocutors. Irrespective of translation, the cultural reference of "lamb" cannot be more suitable to Western Christians. However, the religious connotation of Lamb of God has to make sense to Eskimos through translation. It is true that there exists no such concept as lamb in the tribesmen's psychology. Yet, "seal" is understood in a drastically different way from lamb by Westerners.

Consequently, this paper claims that "lamb" can be replaced by "dog" to adapt to the aboriginals' spirituality given their deep affections to the animal which is no less than those of pet-keepers nowadays. Therefore, "dog" can appropriately replace the source cultural image. According to the cultural turn theory, when contradiction rises between the source culture and the greater culture beyond text, the latter should be prioritized. In this case, "lamb" embodies the source culture while the greater culture reflects the needs of religious transfer to quite an eccentric ethnic group. Thus, it is necessary to adapt the source image to the Eskimo culture.

\section{Conclusion}

In conclusion, as a significant approach to Translation Studies, the cultural turn theory enables researchers to focus on the greater contextual factors influencing translatorial behavior rather than being myopic of the linguistic details. After all, translation like a historic fact, needs to be considered under a given circumstance. By reviewing and discussing the three major doubts concerning the cultural turn theory, this paper tried to defend the theory as a useful analytical instrument for translation research. Cultural turn theory also broadens our vision into the possibilities of researching translation from the far more excitingly new ways such as ideology, politics, history and so on, which entail a fine balance between text and context.

\section{Acknowledgement}

This research was financially supported by the Fundamental Research Funds for the Central Universities, PRC on the program "On the Foreignizing Translation Trend from the Perspective of Cultural Turn” (program code: 20110831).

\section{References}

[1] M. Snell-Hornby, Translation Studies: An Integrated Approach. Amsterdam and Philadelphia: John Benjamins, 1988.

[2] M. Snell-Hornby, Linguistic Transcoding or Cultural Transfer. In S. Bassnett and A. Lefevere (eds). Translation, History and Culture. pp.79-86. London: Pinter, 1990. 
[3] A. Lefevere, Translation, Rewriting, and the Manipulation of Literary Fame. London and New York: Routledge, 1992.

[4] A. Lefevere, Chinese and Western Thinking on Translation. In S. Bassnett and A. Lefevere (eds). Constructing Cultures. Essays on Literary Translation. pp.12-24. Clevedon: Multilingual Matters, 1998.

[5] S. Bassnett, Translation Studies, 4th Edition. London and New York: Routledge, 2014.

[6] B. Buden and S. Nowotny, Cultural Translation: An Introduction to the Problem. Translation Studies, vol2: pp.196-208, 2009.

[7] E. A, Nida and C. R. Taber, The Theory and Practice of Translation. Leiden: E. J. Brill, 1969.

[8] M. Shuttleworth and M. Cowie, Dictionary of Translation Studies. Manchester: St Jerome, 1997.

[9] B. Hatim, Teaching and Researching Translation. Harlow: Pearson Education, 2013.

[10] S. Bassnett, S. and A. Lefevere, (eds). (1990). Translation, History and Culture. London: Pinter, 1990.

[11] A. Pym, Exploring Translation Theories, 2nd Edition. London and New York: Routledge, 2014.

[12] R. Barthes, Image-Music-Text. New York: Hill and Wang, 1977.

[13]G. Toury, Descriptive Translation Studies - And Beyond. Amsterdam and Philadelphia, PA: John Benjamins, 1995.

[14] K. Malmkjaer, Linguistics and the Language of Translation. Edinburgh: Edinburgh University Press, 2005.

[15] A. Chesterman and E. Wagner, Can Theory Help Translators? A Dialogue between the Ivory Tower and the Wordface. Manchester: St Jerome, 2002. 